\title{
Síndrome de Ativação Macrofágica em Paciente com Lúpus Eritematoso Sistêmico Juvenil
}

\section{Macrophase Activation Syndrome in a Patient with Juvenile Systemic Lupus Erythematosus}

\author{
Simone Manso de Carvalho ${ }^{(1)}$, João Henrique do Amaral e Silva ${ }^{(2)}$, Juliana de Oliveira Sato ${ }^{(1)}$, \\ Maria Aparecida Custódio Domingues ${ }^{(3)}$, Claudia Saad Magalhães ${ }^{(4)}$
}

\section{RESUMO}

A hemofagocitose reativa ou síndrome de ativação macrofágica (SAM) é uma complicação das doenças inflamatórias sistêmicas, causada por expansão de células T e macrófagos, com produção maciça de citocinas pró-inflamatórias, ocorrendo mais freqüentemente na artrite idiopática juvenil sistêmica e raramente no lúpus eritematoso sistêmico juvenil (LESJ). Objetivo: Relatar um caso de LESJ que evoluiu com SAM precipitada por infecção e infarto esplênico, com desfecho fatal. Relato de caso: Uma menina de 7 anos, com diagnóstico de LESJ desde os 5 anos, evoluiu com artrite em atividade, alopecia intensa, citopenias, cefaléia, infecções respiratórias recorrentes e elevação intermitente de transaminases. Os anticorpos anti-DNA e anticardiolipina IgG e IgM foram identificados e a biópsia renal evidenciou glomerulonefrite lúpica de classe III. A paciente foi tratada com pulso de metilprednisolona, prednisona, azatioprina e hidroxicloroquina. Após dois anos, na vigência de pneumonia apresentou abdome agudo e convulsões, evoluindo para o choque hemorrágico fatal após esplenectomia, que evidenciou infarto esplênico e infiltração maciça por macrófagos hemofagocíticos CDl63+. Conclusão: A revisão do desfecho sugere a SAM precipitada por infecção e sobreposta a atividade inflamatória do lúpus com febre persistente, citopenias, disfunção hepática, hepatomegalia e esplenomegalia, como efeitos do excesso de produção de citocinas. Os anticorpos anticardiolipina podem ter tido papel precipitante na coagulopatia, que resultou infarto esplênico e choque hemorrágico.

Palavras-chave: hemofagocitose, infecções, lúpus eritematoso sistêmico juvenil, síndrome de ativação macrofágica.

\begin{abstract}
Reactive haemophagocytosis or macrophage activation syndrome (MAS) is a complication of systemic inflammatory disorders, caused by expansion of $T$ cells and haemophagocytic macrophages, with cytokine overproduction. It has been described most often in systemic juvenile idiopathic arthritis and rarely in juvenile systemic lupus erythematosus (JSLE). Objective: To report a JSLE case who developed MAS in association with spleen infarct triggered by infection, with fatal outcome. Case report: A 7-year old-girl diagnosed with lupus since age 5-y developed several episodes of arthritis flare, cytopenias, severe alopecia, headaches and recurrent episodes of respiratory infections with intermittently increased serum transaminases. Anti-DNA and anti-cardiolipin IgG and IgM were identified and Class III lupus glomerulonephritis was diagnosed by renal biopsy. The patient was treated with methylprednisolone pulses, prednisone, azatioprine and hydroxychloroquine. Last admitted due to pneumonia, she evolved into abdominal crisis and seizures, undergoing splenectomy and evolving into haemorragic shock with fatal outcome. A spleen infarct was found and anti-CDI63 antibodies staining disclosed intense haemophagocytic macrophage infiltration. Conclusion: This outcome suggests infection-triggered MAS overlapping lupus flare with persistent fever, cytopenia, liver dysfunction, hepatomegaly and splenomegaly as cytokine excess driven effect. Anti-cardiolipin antibodies may also had a coagulopathy precipiting role.
\end{abstract}

Keywords: haemophagocytosis, infections, juvenile systemic lupus erythematosus, macrophage activation syndrome.

\footnotetext{
Recebido em 16/11/2007. Aprovado, após revisão, em 14/7/2008. Declaramos a inexistência de conflitos de interesse.

Faculdade de Medicina de Botucatu da Universidade Estadual Paulista (Unesp).

1. Especializanda em Reumatologia Pediátrica pelo Departamento de Pediatria da Faculdade de Medicina de Botucatu da Unesp

2. Residente de Patologia do Departamento de Patologia da Faculdade de Medicina de Botucatu da Unesp.

3. Professora-assistente do Departamento de Patologia da Faculdade de Medicina de Botucatu da Unesp.

4. Professora adjunta, livre-docente em Reumatologia Pediátrica do Departamento de Pediatria da Faculdade de Medicina de Botucatu da Unesp.

Endereço para correspondência: Claudia Saad Magalhães, Departamento de Pediatria, Anexo D, Faculdade de Medicina de Botucatu, Unesp, 18618-970, Botucatu,

SP, e-mail: claudi@fmb.unesp.br
} 


\section{INTRODUÇÃO}

A hemofagocitose reativa ou síndrome de ativação macrofágica (SAM) é uma complicação rara de doenças inflamatórias sistêmicas, sendo potencialmente fatal pela produção maciça de citocinas pró-inflamatórias que determinam as manifestações clínicas, freqüentemente resultando falência de múltiplos órgãos. O quadro clínico consiste principalmente de febre, hepatoesplenomegalia, pancitopenia, linfadenopatia, envolvimento neurológico e coagulopatia de consumo ${ }^{(1,2)}$.

Esta síndrome combina a disfunção de células NK (natural killer) e células $\mathrm{T}$ citotóxicas ${ }^{(3,4)}$. Os sistemas fundamentados na proteína perforina estão envolvidos na regulação imunológica, com a lise osmótica de grânulos de neutrófilos e células NK. As mutações nos genes da perforina determinam alterações imunorregulatórias ${ }^{(5)}$ e resposta anormal de células $\mathrm{T}$ aos agentes etiológicos desconhecidos, resultando a hemofagocitose linfohistiocítica familiar ${ }^{(3)}$. A ativação macrofágica pode ocorrer também associada com infecções sistêmicas, imunodeficiências, doenças linfoproliferativas e auto-imunes. Entre estas, a artrite idiopática juvenil (AIJ) sistêmica é a mais freqüentemente descrita durante a apresentação e no curso da doença ${ }^{(2,3,6,7)}$. Não há protocolo terapêutico padronizado, mas reconhece-se atualmente que o tratamento precoce com altas doses de metilprednisolona por via parenteral e ciclosporina A influenciam o prognóstico no caso das doenças auto-imunes ${ }^{(8)}$. Entre outros tratamentos incluem-se o etoposide, a imunoglobulina intravenosa, a ciclofosfamida, a plasmaférese e o etanercepte ${ }^{(8)}$, assim como os antagonistas anti-ILl-beta, recentemente descritos ${ }^{(9)}$.

A SAM tem sido observada mais freqüentemente na AIJ sistêmica, sendo relatada em diversas séries de casos, com gravidade variável ${ }^{(2,3,6,7)}$ e esporadicamente em outras doenças auto-imunes, como o lúpus eritematoso sistêmico juvenil (LESJ) $)^{(7,10-13)}$ e a dermatomiosite juvenil ${ }^{(14)}$.

O seu diagnóstico continua sendo um desafio para os clínicos. Ressaltando a importância do seu reconhecimento precoce no curso do LESJ, foi revisado um caso insuspeito, em uma menina de 7 anos com LESJ, que evoluiu com infarto esplênico e hemofagocitose, desencadeados por infecção.

\section{RELATO DE CASO}

O diagnóstico de LESJ foi feito aos 5 anos de idade com a apresentação de febre por oito semanas, astenia, epistaxe, exantema em membros inferiores do tipo púrpura palpável, linfadenomegalia e esplenomegalia. A investigação de infecções bacterianas e virais, por causa da febre persistente após antipiréticos e antibioticoterapia de amplo espectro, revelou hemocultura e urinocultura negativas. O status imunitário avaliado indicava imunizações adequadas para a idade com a exclusão de imunodeficiências primárias, contudo a vacinação antipneumocócica não foi realizada. A punção e a biópsia de medula óssea foram indicadas, mediante leucopenia, plaquetopenia e anemia, afastaram alterações linfoproliferativas. Em poucos dias, ela evoluiu com exantema discóide, fotossensibilidade, aftas orais, dor torácica e derrame pericárdico, proteinúria e hipertensão arterial. O hemograma mostrava leucopenia variando de $3 \times 10^{3}$ a $1 \times 10^{3} / \mathrm{mm}^{3}$, linfopenia $384 / \mathrm{mm}^{3}$, VHS $130 \mathrm{~mm} / \mathrm{h}$, cilindrúria, proteinúria de $0,29 \mathrm{~g} / 24$ horas e clearence de creatinina de $74,2 \mathrm{~mL} / \mathrm{min} / 1,73 \mathrm{~m}^{2}$. Apresentava também anticorpos antinucleares (ANA) positivos com título de 1:1256, anti-DNA 493 UI, anticorpos anticardiolipina IgG 33 GPL (normal até 21 GPL) U/mL e IgM 75 MPL (normal até $21 \mathrm{MPL}$ ) U/mL, C3 24,2 mg\%, (normal 88 a $201 \mathrm{mg} \%$ ), C4 < $5 \mathrm{mg} \%$ (normal 16 a $47 \mathrm{mg} \%$ ), albumina $2,7 \mathrm{mg} \%$ (normal 3,5 a 5,0 mg\%), IgA $300 \mathrm{mg} \%$ (normal 13 a $152 \mathrm{mg} \%$ ), IgG 2338 mg\% (normal 331 a 1187 mg\%), IgM 197 mg\% (normal 41 a 186 mg\%) e IgE 954 UI/mL (normal $<60 \mathrm{UI} / \mathrm{mL}$ ), teste de Coombs negativo. A biópsia renal resultou glomerulonefrite mesangial proliferativa de classe III com fibrose intersticial, índice de Austin 3 para atividade e 2 para cronicidade e depósitos de IgG, IgM, $\mathrm{IgA}, \mathrm{Clq}$ e $\mathrm{C} 3 \mathrm{em}$ alças capilares e mesângio. O diagnóstico de LESJ foi inequívoco, perfazendo dez dos 11 critérios do American College of Rheumatology (ACR) e com índice de atividade de 30 (SLEDAI 0-105) (15). $^{(1)}$

O tratamento foi iniciado com pulsos de metilprednisolona e subseqüentemente com prednisona oral $(2 \mathrm{mg} /$ $\mathrm{kg} /$ dia $)$, azatioprina $(2,5 \mathrm{mg} / \mathrm{kg} /$ dia $)$, hidroxicloroquina $(6 \mathrm{mg} / \mathrm{kg} / \mathrm{dia})$, tratamento anti-hipertensivo com enalapril $(0,5 \mathrm{mg} / \mathrm{kg} /$ dia $)$ e propanolol (20 mg/dia), ácido fólico ( $1 \mathrm{mg} /$ dia $)$, suplementação de cálcio $(0,5 \mathrm{~g} /$ dia $)$ e vitamina $\mathrm{D}$ (400 U/dia). Houve estabilização do quadro com redução gradual da prednisona, mantendo-se a paciente clinicamente estável por um ano e meio, quando reiniciaram febre, exantema após exposição solar, alopecia intensa, úlceras orais, hepatomegalia e elevação das transaminases. Todas as sorologias foram reavaliadas, incluindo hepatite, citomegalovírus e mononucleose, sendo todas negativas. Mantinha as citopenias com VHS elevado, elevação intermitente das transaminases séricas, dores torácicas 
e infecções respiratórias freqüentes. Observou-se resposta parcial aos pulsos de metilprednisolona, tendo recebido três pulsos no período de seis meses. Após um período curto de estabilidade, foi admitida na emergência e unidade de terapia intensiva com quadro de dispnéia, distensão abdominal, sendo diagnosticada pneumonia e a hemocultura resultou positiva (Streptococcus pneumoniae), sendo tratada com ceftriaxona. Durante a hospitalização houve rápida deterioração do estado geral, evoluindo com convulsões, distensão abdominal e abdome agudo. A ultra-sonografia abdominal revelou esplenomegalia com múltiplas imagens hipoecogênicas no baço. Foi submetida a esplenectomia de emergência evoluindo com choque hemorrágico e óbito. A autópsia não foi autorizada e o exame histopatológico do baço revelou infarto, vasculite esplênica típica e hemofagocitose, documentada pela marcação com anticorpos anti-CD 163 ${ }^{(16)}$ (Figura 1).

A revisão do curso clínico e laboratorial, assim como o exame histopatológico do baço sugeriram a síndrome de ativação macrofágica, ocorrendo em sobreposição com a atividade inflamatória do lúpus, e tendo como fatores precipitantes as infecções intercorrentes e a coagulopatia.

\section{DISCUSSÃO}

O diagnóstico de SAM ocorrendo em associação com a atividade inflamatória do lúpus e precipitada por infecções alerta para alguns aspectos. A SAM representa os aspectos clínicos e laboratoriais da hiperprodução de citocinas e ativação de macrófagos diferenciados (histiócitos), contudo ainda não há critérios diagnósticos padronizados. A identificação da SAM secundária ao lúpus é difícil pois, febre, pancitopenia, linfadenopatia, manifestações neurológicas, artrite, exantema, hepatomegalia, manifestações renais e cardíacas, aumento da DHL também fazem parte da atividade inflamatória da própria doença. Entretanto, há manifestações específicas, como a hiperferritinemia, a hipofibrinogenemia, a disfunção hepática, a esplenomegalia e a hemofagocitose no aspirado da medula óssea. A queda paradoxal da VHS secundária à hipofibrinogenemia também é sugestiva ${ }^{(1)}$. Todavia, no presente relato, a suspeita clínica não foi confirmada por meio de exames, pois o quadro se instalou agudamente após episódio infeccioso e o diagnóstico de hemofagocitose foi post mortem.

Há relatos recentes sugerindo que a maior dificuldade de diagnosticar a SAM em pacientes lúpicos encontra-se na semelhança das manifestações clínicas infecciosas e de atividade da doença, já que no caso do LESJ associado com
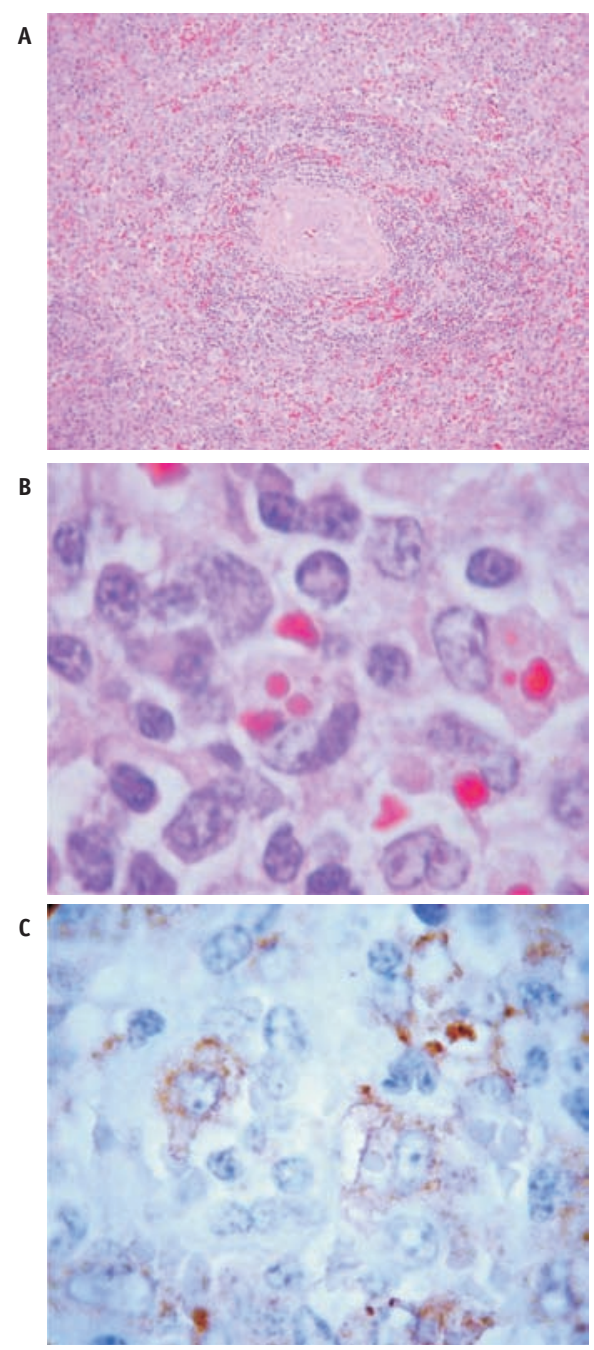

Figura 1 - Aspectos histopatólogicos esplênicos: a) vasculite típica do lúpus eritematoso sistêmico do tipo arteríolas "em casca de cebola"; b) hemofagociose por meio de coloração HE; c) de marcação com o anticorpo anti-CD163 (hemoglobin-haptoglobin scavenger receptor), identificando macrófagos em processo de ativação.

a SAM, as manifestações são insidiosas e de diagnóstico diferencial complexo ${ }^{(17)}$. No presente caso, o quadro se desenvolveu durante a corticoterapia e imunossupressão com azatioprina, indicada mediante a glomerulonefrite. No entanto, a verificação de intercorrências infecciosas como a pneumonia por pneumococo, que levou a este desfecho, pode ter tido papel desencadeante e agravado por fenômeno vascular associado. A identificação de vasculite típica do tipo arteríolas em "casca de cebola” no baço (Figura la), a presença de títulos elevados de anticorpos anticardiolipina, assim como a evidência de ativação macrofágica que resultou pancitopenia e coagulopatia ${ }^{(4)}$, sugerem este componente vascular. A hemofagocitose caracterizada pelo consumo de 
elementos hematopoiéticos na medula óssea pode agravar as citopenias e combinada com a produção de fatores tissulares pró-coagulantes e aos efeitos do TNF-alfa no endotélio vascular, durante a atividade de doença sistêmica inflamatória, poderia também ter contribuído para a coagulopatia.

A deficiência ou a disfunção primária em células NK levaria à persistência de replicação viral e à expansão maciça de células CD8 citotóxicas, como principal mecanismo da ativação macrofágica ${ }^{(4)}$. As alterações de células NK também foram descritas no lúpus ${ }^{(18)}$ e poderiam ter contribuído como fator agravante. Entre as causas possíveis para o infarto esplênico incluem-se a coagulopatia e os fatores pró-trombóticos associados com anticorpos anticardiolipina $^{(19)}$. Embora a documentação da coagulação

\section{REFERÊNCIAS}

1. Ravelli A: Macrophage activation syndrome. Curr Opin Rheumatol 14: 548-52, 2002.

2. Sawhney S, Woo P, Murray KJ: Macrophage activation syndrome: a potentially fatal complication of rheumatic disorders. Arch Dis Child 85: 421-6, 2001.

3. Grom AA: Macrophage activation syndrome and reactive haemophagocytic lymphohistiocytosis: the same entities? Curr Opin Rheumatol 15: 587-90, 2003.

4. Grom AA: Natural killer cell dysfunction: a common pathway in systemic-onset juvenile rheumatoid arthritis, macrophage activation syndrome and hemophagocytic lymphohistiocytosis? Arthritis Rheum 50: 689-98, 2004.

5. Wulffraat NM, Rijkers GT, Elst E, et al.: Reduced perforin expression in systemic juvenile idiopathic arthritis is restored by autologous stem-cell transplantation. Rheumatology 42: 375-9, 2003.

6. Silva CAA, Silva CHM, Robazzi TCMV, et al.: Macrophage activation syndrome associated with systemic onset juvenile idiopathic arthritis. J Pediatr (Rio J) 80: 517-22, 2004.

7. Avcin T, Tse SML, Schineider R, Silverman ED: Macrophage activation syndrome as the presenting manifestation of rheumatic diseases in childhood. J Pediatr 148: 683-6, 2006.

8. Stephan JL, Kone-Paut I, Galambrun C, et al.: Reactive haemophagocytic syndrome in children with inflammatory disorders. A retrospective review of 24 patients. Rheumatology (Oxford) 40: 1285-92, 2001.

9. Behrens EM, Kreiger PA, Cherian S, Cron RQ: Interleukin 1 receptor antagonist to treat cytophagic histiocytic panniculitis with secondary hemophagocytic lymphohistiocytosis. J Rheumatol 33: 2081-4, 2006.

10. Javier RM, Sibilia J, Offner C, et al.: Macrophage activation in lupus patients. Rev Rheum (Engl Ed) 60: 714-8, 1993.

11. Papo T, Andre MH, Amoura Z, et al.: The spectrum of reactive hemopagocytic syndrome in systemic lupus erythematosus. J Rheumatol 26: 927-30, 1999. intravascular disseminada, por meio de testes de coagulação e da autópsia, também não tenha sido possível, a presença do infarto esplênico e do choque hemorrágico conduzem a esta hipótese. Casos de infarto esplênico "silencioso" têm sido relatados no LESJ ${ }^{(20)}$, assim como o infarto precipitado por infecções respiratórias ${ }^{(19)}$.

Em conclusão, este caso alerta para a necessidade de intervenção oportuna e medidas preventivas para o controle de infecções virais e bacterianas, como vacinação antipneumocócica e, sobretudo, na presença da síndrome antifosfolípide, pois no lúpus estes fatores estão relacionados com a mortalidade. A aspiração e a punção biópsia da medula óssea têm sido recomendadas como investigação rotineira mediante as citopenias febris no lúpus pediátrico ${ }^{(17)}$.

12. Isome M, Suzuki J, Takahashi A, et al.: Epstein-Barr virusassociated hemophagocytic syndrome in a patient with lupus nephritis. Pediatr Nephrol 20: 226-36, 2005.

13. McCann LJ, Hasson N, Pilkington CA: Macrophage activation syndrome as an early presentation of lupus. J Rheumatol 33: 438-40, 2006.

14. Kobayashi I, Yamada M, Kawamura N, et al.: Platelet-specific hemophagocytosis in a patient with juvenile dermatomyositis. Acta Paediatr 89: 617-9, 2000.

15. Brunner HI, Feldman BM, Bombardier C, Silvermann ED: Sensitivity of the systemic lupus erythematosus disease activity index, British Isles lupus assessment group index, and systemic lupus activity measure in the evaluation of clinical change in childhood-onset systemic lupus erythematosus. Arthritis Rheum 42: 1354-60, 1999.

16. Blessing J, Prada A, Siegel DM, et al.: The diagnostic significance of soluble CD 163 and soluble interleukin-2 receptor alpha-chain in macrophage activation syndrome and untreated new-onset systemic juvenile idiopathic arthritis. Arthritis Rheum 65: 965-71, 2007.

17. Pringe A, Trail L, Ruperto N, et al.: Macrophage activation syndrome in juvenile systemic erythematosus lupus: an underrecognized complication? Lupus 16: 587-3, 2007

18. Yahubara A, Yang FC, Nakazawa T, et al.: A killing defect of natural killer cells as an underlying immunologic abnormality in childhood systemic lupus erythematosus. J Rheumatol 23: 171-7, 1996.

19. Witmer CM, Steenhoff AP, Shah SS, Raffini LJ: Mycoplasma pneumoniae, splenic infarct and transient antiphospholipid antibodies: a new association?. Pediatrics 119: e292-5, 2007.

20. Constantin T, Ponyi A, Varga E, et al.: Antiphospholipid syndrome accompanied by a silent spleen infarct in a patient with juvenile SLE. Rheumatol Int 26: 951-2, 2006. 